\title{
Smart-glasses: exposing and elucidating the ethical issues
}

Bjørn Hofmann ${ }^{1,2}$, Dušan Haustein ${ }^{3}$, and Laurens Landeweerd ${ }^{4,5}$

1. Norwegian University of Science and Technology, Gjøvik

2. Centre for Medical Ethics, University of Oslo, Norway

3. New Technologies Research Centre, University of West Bohemia, Czech republic

4. Oslo and Akershus University College of Applied Sciences (HiOA), Norway

5. Radboud University, Nimegen, the Netherlands

\section{Corresponding author:}

Bjørn Hofmann, b.m.hofmann@medisin.uio.no

Centre for Medical Ethics,

University of Oslo

PO Box 1130, Blindern

$\mathrm{N}-0318$ Oslo 


\title{
Smart-glasses: exposing and elucidating the ethical issues
}

\begin{abstract}
:
Objective: To provide an overview over ethical issues relevant to the assessment, implementation, and use of smart-glasses. The purpose of the overview is to facilitate deliberation, decision making, and the formation of knowledge and norms for this emerging technology.
\end{abstract}

Method: An axiological question-based method for human cognitive enhancement including an extensive literature search on smart-glasses is used to identify relevant ethical issues. The search is supplemented with relevant ethical issues identified in the literature on human cognitive enhancement (in general) and in the study of technical aspects of smart-glasses. Identified papers were subject to traditional content analysis.

Results: 739 references were identified, 247 were identified to be relevant for full text examinations, and 155 were included in the study. A wide range of the ethical issues are identified. Amongst them are privacy, safety, justice, as well as change in human agency, accountability, responsibility, and social interaction. So were power- and ideology issues.

Conclusion: A wide variety of ethical issues with smart-glasses have been identified, such as issues related to privacy, safety, justice, change in human agency, accountability, responsibility, social interaction, power and ideology. Smart-glasses are envisioned to change individual human identity and behavior as well as social interaction. Taking these issues into account appears to be relevant when developing, deliberating, deciding on, implementing, and using smart-glasses.

Key words: Smart-glasses, autonomy, authenticity, agency, privacy, safety 


\section{Introduction}

Smart-glasses promises "to be one of the latest and most ground-breaking technologies in current times" (Kumar and Sharma 2014). The process of combining actual and virtual reality creates augmented reality (Milgram et al. 2012). Because smart-glasses do not significantly distort vision for the wearer, an illusion of coalescence between actual and virtual elements is achieved, in contrast to virtual reality devices that tend to immerse the user more.

\section{What are smart-glasses and how are they used?}

"Smart-glasses," "Digital Eye Glass," "eye glass display," or "Personal Imaging Systems" are wearable devices that display images to the visual field of a user. They are designed to add visual elements to the visual experience of a person without significantly distorting or disturbing the person's ordinary vision, qua use, interaction with the actual world and qua experience.

The devices involved vary but they do not merely display virtual elements that stand apart from the direct living environment. They often feature processing capacity that is similar to a smartphone or GPS. This shifts smart-glasses beyond the group of passive head-mounted displays. Moreover, devices like these do not only display information, but can also use the variety of sensors to track, analyse, distribute, and store data about the surrounding environment as well as the user. Among sensors and input devices are: accelerometers, magnetometers, GPS, microphones, touchpads, eyetracking cameras etc. Data from these sensors can be utilized either by smart-glasses' own processing unit itself or by a computer, usually a smartphone, connected to the glasses. These features allows utilizing smart-glasses in a variety of scenarios (Steve Mann 2014).

Smart-glasses can connect to the Internet and can access a wide range of data sources, e.g., maps, news, messages, and emails. They can track eye-movements and present marketers with a heat-map of goods the costumers look at the most. They can recognize places and faces and display information and social media profiles of people the smart glasses user is looking at. Smart-glasses are already applied in medicine, and are envisioned to have a wide range of applications in this field (Singh et al. ; Moshtaghi et al. 2015; Hetterich et al. 2014; Mentler et al. 2015; Klein et al. 2015; S. Mitrasinovic et al. 2015; Maas et al. 2015; Rankin et al. 2015), education (Ikonen and Knutas ; Labus et al. 2015; Freina and Ott 2015), tourism (Harasymowicz 2015), social science research (Paterson and Glass 2015), navigation (Ostendorp et al. 2015; Higuchi et al. 2015), crowd steering (Borean et al. 2015), activity recognition (Zhan 2014; Betancourt et al. 2015) including diet recognition and food behavior control (Gemming et al. 2013; Farinella et al. 2014), mood (engagement) measurement (Kunze et al. 2015), forensics (Karabiyik 2015), promoting cultural sustainability (Irving and Hoffman 2014), promoting teamwork and safety (Moshtaghi et al. 2015) and they can also be used for military purposes. Prototypes and applications exist in several of these fields. E.g., within health care, a wide range of applications have been identified, such as hands-free photo and video documentation, telemedicine, Electronic Health Record retrieval and input, rapid diagnostic test analysis, education, and live broadcasting (Stefan Mitrasinovic et al. 2015), as well as health promotion (Edington et al. 2015).

These are only a fraction of possible scenarios for smart-glass applications. And it is clear that each brings a series of ethical questions that need to be answered.

\section{Which group is involved in the use of the technology?}


Smart-glasses have a broad range of potential users. Similar to smartphones, they are designed to be

\section{Methods}

We followed an axiological question-based approach to identify ethical issues relevant for decisionmakers, which is used in health technology assessment (HTA)(B. Hofmann et al. 2014), and has been developed for use in the field of human cognitive enhancement (B. Hofmann Submitted 2016). Question-based methods are well known in the literature on ethical issues of human enhancement (Allhoff et al. 2009). Although the approach may be used as a checklist, it may also be used as an input for and as a guide for processual forms of technology assessment, e.g., ethical-constructive technology assessment (Kiran et al. 2015).

As part of the axiological question-based approach, we performed a literature search on smartglasses in order to identify ethical issues relevant for assessing the technology. An initial search on PubMed did not result in any relevant references. A search in Google Scholar was performed with the search string ("smart glasses" OR "smart glasses" OR "digital eye glass" OR "personal imaging system" OR "eyeglass display") AND (ethics OR ethical OR moral OR benefit OR therapy OR harm OR hazard OR distortion OR privacy OR authenticity OR integrity OR "selfhood"). All identified references were investigated with respect to relevance to the various questions of the approach (Cross reference to methods paper). Conventional qualitative content analysis (Hsieh and Shannon 2005) of the identified papers in full text was performed to identify ethical issues. Identified ethical issues were grouped in accordance with the questions. Issues not addressed by any questions were highlighted 
and questions not covered by any identified issues were analyzed on basis of the content of the articles to see if there are ethical issues that have not been identified by the literature.

While the method aims at comprehensiveness in covering all ethical issues, it does not aim at being exhaustive in identifying all references addressing the same issue. When a certain issue is identified in a significant number of references and including more references for the same issue does not add new information, further references are not included. The number of times an issue is mentioned in the literature does not add value, as some references only mention that there are ethical issues without providing any analysis and as controversial statements may generate a lot of responses without added value (i.e., "noise").

\section{Results}

The literature search identified 739 references. 247 references were found relevant for identifying ethical issues with smart-glasses and were examined full text. 155 of these references were included for content analysis of the full-text items. The results of the search strategy are shown in Figure 1.

Figure 1 Search strategy results

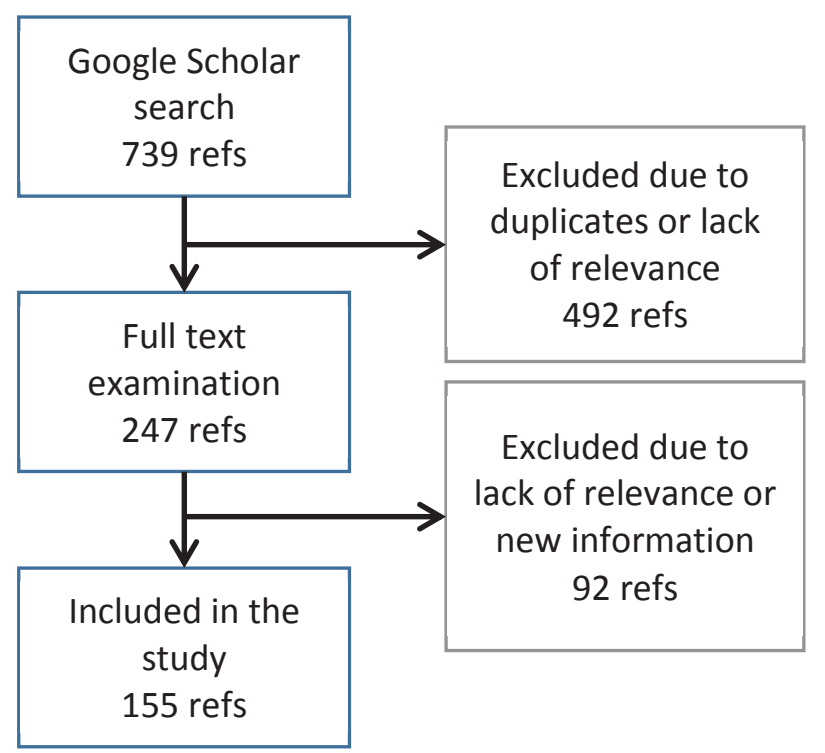

A wide range of ethical issues were identified. Organized by the questions of the axiological approach they will be presented below grouped under suitable headings to increase readability and avoid fragmentation.

\section{Benefits and harms}

Experiences and reports on benefits and harms vary amongst users and types of smart-glasses (Koelle et al.). Some important issues highlighted in the literature are summarized in Table 1.

Table 1 Overview of potential benefits and harms identified in the literature

\begin{tabular}{|l|c|}
\hline Potential benefits & Potential harms \\
\hline $\begin{array}{l}\text { Smart-glasses may become an extensions of } \\
\text { human body and mind (Huang 2013) and } \\
\text { enhance our interaction with the } \\
\text { environment (Benessia and Pereira 2015) }\end{array}$ & $\begin{array}{l}\text { Make people feel uncomfortable (Wolf et al. } \\
\text { below) }\end{array}$ \\
\hline Alter (improve) health behavior (Doherty et & May make people dependent (Bendel 2014) \\
\hline
\end{tabular}




\begin{tabular}{|c|c|}
\hline al. 2013). & \\
\hline $\begin{array}{l}\text { Block unpleasant experiences and avoid } \\
\text { anxiety (in a hospital setting)(Tse et al. 2002) } \\
\text { and to support patients with specific needs } \\
\text { (of care) (Hetterich et al. 2014) }\end{array}$ & $\begin{array}{l}\text { Psychological and health risks with smart- } \\
\text { glasses have been pointed out (Jacquemard } \\
\text { et al. 2014) }\end{array}$ \\
\hline $\begin{array}{l}\text { Making learning more efficient or create } \\
\text { new learning modes(Koper 2014). However, } \\
\text { the outcomes of learning with smart-glasses } \\
\text { are mixed (Sapargaliyev 2015) }\end{array}$ & $\begin{array}{l}\text { Safety aspects are also identified in the use } \\
\text { of smart-glasses, e.g., in (pervasive) gaming } \\
\text { (Valente et al. 2015) or navigation (Jones } \\
\text { 2014) }\end{array}$ \\
\hline $\begin{array}{l}\text { Provide safety and security, e.g., for persons } \\
\text { with various forms of impairment, such as } \\
\text { detecting hazards for persons with visual } \\
\text { impairment (He et al. 2015), or in the } \\
\text { industry (Neira Millan 2013) }\end{array}$ & $\begin{array}{l}\text { Smart-glasses are envisioned to threaten } \\
\text { security (Boissier and Castelfranchi 2015) as } \\
\text { information about a person and his or her } \\
\text { behavior may become accessible by others } \\
\text { (Nyang et al. 2014). }\end{array}$ \\
\hline $\begin{array}{l}\text { Smart-glasses may increase situational } \\
\text { awareness (Ackerman 2012), multitasking } \\
\text { abilities (Nikolov 2013), and orientation } \\
\text { (Muschiol 2015) }\end{array}$ & May make people dependent (Bendel 2014) \\
\hline $\begin{array}{l}\text { Assist recognizing and remembering } \\
\text { (Iwamura et al. 2014) as well as impede } \\
\text { forgetting (Jacquemard et al. 2014) }\end{array}$ & $\begin{array}{l}\text { Psychological and health risks with smart- } \\
\text { glasses have been pointed out (Jacquemard } \\
\text { et al. 2014) }\end{array}$ \\
\hline $\begin{array}{l}\text { Be a valuable extension of the human brain } \\
\text { (Bendel 2014) and predicting cognitive } \\
\text { states (Henderson et al. 2013) }\end{array}$ & $\begin{array}{l}\text { Safety aspects are also identified in the use } \\
\text { of smart-glasses, e.g., in (pervasive) gaming } \\
\text { (Valente et al. 2015) or navigation (Jones } \\
\text { 2014) }\end{array}$ \\
\hline $\begin{array}{l}\text { Increase power through the aggregation of } \\
\text { data, e.g., images (Bendel 2014). }\end{array}$ & $\begin{array}{l}\text { Distraction and information overload (Ranck } \\
\text { 2012) }\end{array}$ \\
\hline $\begin{array}{l}\text { Smart-glasses are envisioned to improve } \\
\text { security (Sehgal et al. 2015), e.g., of elderly } \\
\text { by preventing crimes (by saving events in the } \\
\text { could) }\end{array}$ & $\begin{array}{l}\text { Potential exploitation and steering (Borean } \\
\text { et al. 2015), leak of sensitive information } \\
\text { (Shen et al. 2015) }\end{array}$ \\
\hline $\begin{array}{l}\text { Compensate for impaired functions, such as } \\
\text { landmark identification for persons with } \\
\text { reduced visual ability (Ugulino and Fuks } \\
\text { 2015) increasing their quality of life (He et al. } \\
\text { 2015) }\end{array}$ & Breach of privacy (See section below) \\
\hline $\begin{array}{l}\text { User empowerment, self-sufficiency and } \\
\text { inclusion in decision making, and new } \\
\text { business models through open hardware, } \\
\text { open software, and open data (Romano and } \\
\text { Cangiano 2015) }\end{array}$ & $\begin{array}{l}\text { Uncomfortable to wear (Page 2015; Ajmi } \\
\text { and Robak 2015) (physically and socially) }\end{array}$ \\
\hline $\begin{array}{l}\text { Opens for multidisciplinary collaboration } \\
\text { (Ranck 2012) }\end{array}$ & $\begin{array}{l}\text { Potential non-sustainable augmentation or } \\
\text { enhancement }\end{array}$ \\
\hline $\begin{array}{l}\text { Facilitate communication across language } \\
\text { and culture barriers (Kaeri et al. 2015) }\end{array}$ & $\begin{array}{l}\text { Negative reactions (verbally or physical) by } \\
\text { people in public spaces (Wolf et al. 2014). }\end{array}$ \\
\hline $\begin{array}{l}\text { Provide evidence and facilitate litigation } \\
\text { (Bergman 2013) }\end{array}$ & $\begin{array}{l}\text { May reduce some cognitive capacities as } \\
\text { they are "outsourced" to technology, e.g., } \\
\text { navigation skills, or delegate crucial tasks to } \\
\text { less skilled personnel. }\end{array}$ \\
\hline
\end{tabular}


It is important to notice that the same effect may have both positive and negative implications. E.g., distraction can be negative for attentiveness but positive for pain distraction (Triberti et al. 2014).

\section{Health effects}

More specifically a series of health effects are discussed in the literature, such as various eye effects (B. L. Due 2014). None of the studies present high quality evidence, as smart-glass use is not yet so frequent. However, as informed by the precautionary principle, absence of evidence is not evidence of absence of a health effect. Therefore, initial findings are reported.

Smart-glasses use wireless technologies to transmit data. This poses a risk of exposure to potentially harmful levels of electro-magnetic radiation (Organization 2011), especially so when these devices are to be worn on one's head for prolonged periods of time (Markov 2015).

The display of the smart-glasses is located very close to the users' eyes. This forces them to direct their gaze towards a small and bright spot in a potentially uncomfortable space of their visual field. This strains the eyes and may cause asthenopia (an ophthalmological condition characterized by nonspecific symptoms such as fatigue, pain in or around the eyes) (Behar-Cohen et al. 2011; Pan et al. 2012).

The blue-rich LED-based displays of the majority of smart-glasses can hasten macular degeneration. Although there is no evidence this is the case for humans, animal experiments with LED light discovered greatly hastened macular degeneration (Sliney 1984; Shang et al. 2014). Additionally, blue-rich displays are also known to influence the circadian rhythms of their users by suppressing the hormone melatonin levels which aids sleep (Cajochen et al. 2011).

Moreover, users may feel nausea and motion-sickness while using smart-glasses that obstruct their field of view. This is more likely to happen with fully immersive head-mounted displays, as they cover the entire field of view, but users sensitive to the disconnect between the moving virtual information and their stationary body may experience blurred vision, disorientation, or nausea (Chang et al. 2012; Falahee et al. 2000).

\section{Challenging privacy}

Data security and privacy are without doubt the issues that were mentioned and discussed most widely in the identified literature (M. J. Egenhofer and Kuhn 1998; M. Egenhofer 1999; Thiel and Thiel 2014; Lerch 2014; Koren and Klamma 2015; Boissier and Castelfranchi 2015; Ling et al. 2014; Jacquemard et al. 2014; Yoon et al. 2015; Satyanarayanan et al. 2015; Kumar and Sharma 2014; Arnold et al. 2015; Haris et al. 2014; Kotsios 2015; Speed et al. 2013; S. I. Friedland 2015; Chalfen 2014). The filming and recording function of smart glasses makes it possible to "broadcast," identify, and follow persons and events, making people constantly followed (Tunçalp and Fagan 2014). Smartglass systems can be eavesdropped, seen, or recorded by unauthorized parties (Forte et al. 2014). Smart-glass use makes it impossible to know whether you are recorded (Dainow 2014). Face recognition functions with smart-glasses challenges individuals' ability to remain anonymous in public places (Welinder 2013). Although identification is acknowledged to have a range of beneficial uses, it may also reduce people's ability to "go under the radar" and it is argued that it calls for regulatory reflection and responses (Welinder 2013). Some manufacturers address these issues by adding a 'privacy indicator' light to their smart-glasses, like the latest M300 model from the company Vuzix. Negative reactions (even physical assault) towards people wearing smart-glasses in public places have been reported (Wolf et al. 2014), and such reactions may depend on cultural context, place and time. 
Smart-glasses can be used to monitor a person's level of attention (Lee and Balan 2014) and they are

Noble and Roberts 2016) on the one hand. Employee location monitoring is identified as one potential challenge. On the other hand, sousveilance ('undersight', computationally mediated veillances) is identified as a beneficial potential (McKenna et al. ; Sebastian Mann 2013; Steve Mann and Ferenbok 2013), foreseen to protect the wearer of smart-glasses and to balance the harms from surveillance (Steve Mann 2012).

As smart-glasses are envisioned to be a useful tool for health monitoring, such uses strongly enforce the issues of privacy and authenticity (Takei et al. 2015). When elaborating and enforcing regulations, it was recommended to differentiate between self-monitoring and the capturing or monitoring of others (Thiel and Thiel 2014).

Issues such as intrusiveness, transparency, and challenges with obtaining informed consent were highlighted (Doherty et al. 2013). Solutions to some of these issues were also suggested, e.g., assuring limited resolution in public spaces (Satyanarayanan et al. 2015) and the development of various protocols (Zhang et al. 2014b).

\section{Changing the human condition(s)}

It was pointed out that smart-glasses can distort our perception (Jacquemard et al. 2014), "modify our perception and the world," or more directly "modify our world and ourselves" (Liberati and Nagataki 2015). According to a postphenomenological perspective (Ihde et al. 2015; Rosenberger and Verbeek 2015), smart-glasses can change the way we perceive and act in the world (Harg 2014). Moreover, it is argued that they merge the physical and digital world (Bailey 2014). Smart-glasses can also change our way of learning, e.g., by promoting our learning by being ("Praxistemology") (Sebastian Mann and Hrelja 2013)

The glasses become part of the person (Bendel 2014) and they shape human actions and experiences (Verbeek) and augment the real world with a virtual aspect, in so called "reality shifting"(Pedersen 2013). Smart-glasses can also be seen as part of a fragmented human enhancement (being a specific part of cognitive enhancement) enhancing the fragmentation of human abilities (Lucivero and Vedder 2013). Smart-glasses can be used to focus attention and intention (Zhang et al. 2014a) potentially changing human interaction. Accordingly, altering behavior and sociality has been identified as one potential challenge (Valente et al. 2015). Moreover, reality-altering effects may also induce ethical challenges (Valente et al. 2015), e.g., detachment from reality (Sultan 2015) or blurring the phantasy-reality distinction (Wassom 2014). Social care and health care are foreseen to merge (Michael 2013). Use at home, and in smart-houses (Dauber et al. 2014) may change people's conception of home.

More generally, smart-glasses were identified as threats to human values (Naydler 2013), the responsibility for our actions (Ricci et al. 2015; Pejovic et al. 2015; Wassom 2014), as well as our accountability (Tunçalp and Fagan 2014). E.g., they may extend our responsibility according to extended abilities, e.g. by recording our wrongdoings (Steve Mann 2013). The environmental burden of smart-glasses and related technologies was also discussed (Teehan 2014; Moghaddam et al. 2014).

More fundamentally, smart-glasses are identified to move the boundaries between people (B. L. Due 2014) and may also come to change the conception of the self (Pedersen 2013), as well as human agency (Ricci et al. 2015; Pereira et al. 2013), dignity (Tunçalp and Fagan 2014), and authenticity (Pejovic et al. 2015). They may strongly influence the human mind and body, human capabilities, and the good life (Tunçalp and Fagan 2014). 
Where systems analyze people's desires based on their previous behavior, and assist in fulfilling or enhancing these desires, it may also raise the question of respect for autonomy (Kruijsen 2008).

It has also been pointed out that smart-glasses can change ethics. E.g., action-guiding applications may ensure that our actions are morally acceptable, on the one hand, but reduce our independent ethical reflection, on the other hand (Wassom 2014).

\section{Social interaction}

Social and cultural aspects are identified and discussed (Renzi and de Freitas 2015). Smart-glasses may disturb, disrupt, alter (B. Due 2015), or impair social interaction (Jacquemard et al. 2014) and they may thus call for new social etiquette (B. L. Due 2014). The ability to record every interaction may violate the guarded settings most of social interactions occur in (Ling et al. 2014). Smart-glasses may also find activist applications for social change, e.g., in terms of so-called Maktivism (Steven Mann et al. 2014). Smart-glasses may also result in communicative abundance, which can come to alter the basis of democracies (Keane 2013).

It was also pointed out that technologies such as smart-glasses may get embodied (Verbeek 2015) and change basic conceptions such as "interface," "mediation," and "interaction." (Gill 2015) They may re-configure our self-conception and make its "users reenchant their lives through the spectacular wonder of consumerism and the modern moral narratives of science and technology."(Gallitano 2015) Others are more careful, and argue that you are not what you wear (Marken 2015).

Smart-glasses are also envisioned to change education as students have a significantly different access to information (Chalfen 2014), and Q\&A will be publicly and instantaneously available (Bieber et al. 2015). It may also change social science, as it gives power to the research subject (Chalfen 2014).

\section{Justice}

The issue of justice in the availability and access to the technology has been brought up in the literature (Garcia and Sandler 2008), e.g. in increasing the digital divide (Weber and Zink 2014) in general, or in sports where smart-glasses and other smart-devices can create an unfair advantage for those, who have access to the technology and thus can train more effectively (Bozyer 2015), in particular. Smart-glasses have also been addressed in the perspectives of race, class, and gender (Noble and Roberts 2016). On the other hand, it has been pointed out how smart-glasses may contribute to level the playground (Bendel 2014).

\section{Ideology and power}

The question whether smart-glasses are launched (partly) to increase the data, information, and power of companies such as Google has also been raised (Hedegaard Hansen et al. 2014) and discussed (Noble and Roberts 2016). Others have pointed to the potential to use the technology to nudge or direct people's attention (Morozov 2014) calling for awareness of threats of undue influence, to autonomy, and to democracy. Smart-glasses are also analyzed in terms of commodification of emotions, the "unbridled exploration and intrusion into the physical and emotional space of others," and the "expansion of the surveillance state" (Noble and Roberts 2016).

New technology, such as smart-glasses, combined with Big Data analytics are also identified to point towards pre-crime punishment or the pre-emption of inferred criminal intent (Hildebrandt 2014). Correspondingly, nudging, directing, or ordering people may be possible via smart-glasses. 
It was also often argued that smart-glasses is one example of a technology in a grand movement of solutionism, i.e., a movement where technology is not only a "quick fix" or nails "to the man with the hammer," but more radically, where what is presumed to be pressing problems to be solved are not problems at all (Morozov 2013). Accordingly, the importance addressing the transcendent authority that lies in the expert systems that create the technology has been highlighted (Gallitano 2015).

Smart-glasses are intrinsically biased towards focusing on things and selling products (Benessia and Pereira 2015; Pereira et al. 2013). They contribute to a trend of formatization (Gehmann et al. 2015), i.e., under the guise of promoting liberty, they format our perceptions, conceptions and rationality (Gehmann et al. 2014).

As indicated, informational autonomy and informational justice (fair access to information and ICT) have also been pointed to as important issues to address (Bendel 2014). Another identified issue is that effective use of smart-glasses presupposes trust and can undermine trust and effective use if misused or if they malfunction (Pejovic et al. 2015).

\section{Other rights and legal aspects}

Beyond privacy, regulatory issues mentioned in the literature include image rights (Bendel 2014), as well as data obtained from 'smart' devices used as evidence in court, while the data are obtained without warrant (S. Friedland 2013). In the book Augmented Reality Law, Privacy, and Ethics: Law, Society, and Emerging AR Technologies Brian Wassom discusses a wide range of legal aspects with augmented reality in general, which also are relevant to smart-glasses. Among these are, privacy, litigation procedure, tort and personal injury, property rights, and intellectual property, as well as advertising, marketing, and commerce (Wassom 2014). Smart-glasses may also influence civil rights (Wassom 2014) and become relevant for free speech and discrimination (Roesner et al. 2014).

\section{Other issues not covered by the questions in the axiological approach}

Some related ethical issues are not explicitly covered by the questions of the axiological approach, but identified by the literature search. Technological and cultural obstacles for the uptake of smartglasses is one example of this (Ranck 2012), although this is partly covered by question 14 in the axiological approach. Socio-cultural barriers may bar beneficial (or harmful) implementation and use of a technology. On the other hand, various forms of technological imperatives (B Hofmann 2002), may facilitate such implementation and use.

\section{Questions from the axiological approach, not covered by findings in the literature} Conversely, some questions induced by the axiological approach are not covered by literature identified in the search. These are:

- Does this technology contribute to solving important societal problems, tasks, or challenges? (Q6) Although a wide range of (potential) benefits are highlighted in the literature, none of these are presented as "a problem in need for solution," but rather "a technology looking for problems." (Huff and Munro 1985)

- Can the implementation and use of the technology alter human morality or responsibility? (Q9) Although these issues have been touched upon, they have not been dealt with in great length. The question of what responsibility a person has when acting on information or "advice" presented via smart-glasses appears to need more elaboration than given in the literature. 
- Is it clear how risks arising from the implementation, use or withdrawal of the technology should be handled? (Q17) Although risk and safety issues have been handled, the issue of technology withdrawal has not been mentioned or addressed in the identified literature.

- Are there good existing alternatives to this application? (Q19) This issue has not been discussed.

- Does the technology have potential alternative or dual use? (Q24) Although warfare is mentioned in several articles, this issue has not been extensively addressed in the identified literature.

\section{Methodologies and frameworks identified}

During the literature search and the conjoint conventional content analysis various methods and approaches for addressing ethical issues in cognitive enhancement technologies were identified:

- Agential realist perspective (Barad 2007)(Tunçalp and Fagan 2014).

- Anticipatory technology ethics (Brey 2012)(Tunçalp and Fagan 2014).

- Ethical Constructive Technology Assessment (eCTA, or more precisely, technology accompaniment) (Kiran et al. 2015).

- Ethical Technology Assessment (eTA) (Palm and Hansson 2006).

- Specific framework: An ethical framework for automated, wearable cameras in health behavior research (Kelly et al. 2013).

- Bateson's idea of “total circuits to understand the interrelationship between persons, the social world, and technology (Gillespie and O’Neill 2014).

\section{Discussion}

This article has identified a variety of ethical issues with respect to smart-glasses. Most often mentioned and addressed were privacy issues, but safety, justice, change in human agency, accountability, responsibility, and social interaction were also mentioned or addressed. So were power and ideology issues. Some relevant issues were not mentioned or addressed in the scholarly literature, but were identified by the axiological method. The literature is diverse, and there is no general agreement on the ethical issues or the ranking between them. The literature also covers a lot of contextual ground with respect to types of smart-glasses, applications, users, and settings.

The point here has not been to conclude whether smart-glasses are "good" or "bad." The article does not extend to giving arguments for specific decisions on particular applications, as it is restricted to providing input to the deliberative policy processes. As such, we aimed to provide funders, developers, decision makers, implementers, ethicists, and social scientist with an overview of ethical issues relevant for the development, deliberation, implementation, use, and formation of knowledge and norms with respect to smart-glasses. Not all the identified issues may be relevant for all applications and implementations of smart-glasses. Specific implementation contexts may only actualize certain ethical issues (or none). Moreover, there is a heterogeneity of ethical issues, as there is a heterogeneity of (and use of) smart-glasses. Therefore, it is important to make specific assessments in specific contexts of smart-glasses development, implementation, and use. Although specific context dependent assessments are beyond the scope of this article, we hope that the presented overview will be of value for such specific context dependent assessments.

There are obviously several limitations to the present approach. One of them is that all the arguments regarding the ethical issues identified have not been included or addressed in this study, 
e.g., there are a wide range of specific arguments concerning health hazards with specific smartglasses that have not been explicitly addressed. However, this is not a systematic review of arguments or reasons (Strech and Sofaer 2012), and it is not an full-blown assessment of a specific type of smart-glasses.

Our approach may also be criticized for being eclectic, "impure," and divergent if the aim is to inform deliberations and decisions. This is a highly relevant critique as the approach that we applied addresses a wide range of topics and includes existing (H)TA methodology, e.g., ethical Technology Assessment (eTA) particularly preoccupied with quantifiable risk (Palm and Hansson 2006), "hard impact" (T. Swierstra 2015) and "soft impact" approaches (van der Burg 2009; T. Swierstra and te Molder 2012; T. Swierstra et al. 2009), technological mediations (Verbeek 2011), as well as other approaches (Sollie and Düwell 2009). ${ }^{1}$ Hence, it may generate tension between these methodological elements if the goal is a specific decision. However, the approach is warranted when the aim is to establish a broad, open, and transparent assessment, deliberation, and implementation process.

The applied approach should not be read as a checklist. It is far from obvious that "the moral assessment of new technologies is narrowed down to evaluating a list of pre-defined ethical issues" or that it is principled based (Kiran et al. 2015) in this case. Moreover, the ethical issues identified by this approach are not an end-point for ethical deliberation on smart glasses, but as a starting point for deliberations, decisions, and implementations as well as modifications, negotiations, formation of knowledge, and constitution of moral and social norms and values. Any evolution, constitution, or construction of norms and values (Geels 2005; Boenink et al. 2010; Oudshoorn and Pinch 2003) needs to take as a point of departure the present realm of norms and values.

The literature search performed for this study was also limited to Google Scholar, and it may be argued that searches in the Philosophers Index, Web of Science, EMBASE, ISTPB + ISTP/ISSHP, HTA databases would have added significantly to the identified issues. However, there are very few relevant studies to be identified in these databases, and, as stated in the methods section, the aim of the search was to identify the ethical issues, and not how many times they were mentioned. As the analysis quickly became saturated with the found references, we think that we have been able to identify the most and the important ethical issues with the search strategy. However, we welcome colleagues to perform more extended searches.

This study has some interesting implications. First, it indicates that the scholarly literature may not be sufficient to identify all relevant and/or interesting ethical issues. The questions of the axiological method may identify important ethical issues not yet addressed. Second, the issues identified in this article may be of relevance to (the assessment of) other types of human cognitive enhancement technologies.

It is also important to notice that there has not been a strict quality assessment of the included literature (beyond ordinary scholarly publishing criteria) and the occurrence of the ethical arguments listed. E.g., the studies of smart-glasses' impact on health are not based on rigorous studies (e.g., Randomized Controlled Trials). Many of the other impacts are also quite speculative. There are of course several reasons for including such studies. First, no high quality empirical studies on the outcome of long term smart-glass use are (yet) available. Second, although quite speculative, the foresights can provide relevant scenarios and spur fruitful discussions for the development and implementation of smart-glasses.

\footnotetext{
${ }^{1}$ Although it is beyond the scope of this article to scrutinize to what extent the question-based axiological approach applied here is compatible with other established methods for assessing emerging technologies, this study indicates that there is substantial overlap.
} 
Some readers may find that there is an imbalance in table 1 , finding the benefits more significant than the potential harms. However, it should be noted that this imbalance may as well indicate that smart-glasses are hyped (Ajmi and Robak 2015). It may also stem from the fact that they are developed and promoted by engineers who focus on the technical aspects (Page 2015).

Contextual in-depth ethical analysis of specific smart-glasses is beyond the scope of this study. Our study is limited to providing an overview. Nevertheless, we hope that our systematic synopsis can be a resource for such context-dependent in-depth analysis and inspire contextual in-depth ethical analysis of all the various types and applications of smart-glasses.

\section{Conclusion}

A wide variety of ethical issues with smart-glasses have been identified. Privacy issues were mentioned and addressed most frequently. Safety, justice, change in human agency, accountability, responsibility, social interaction, power and ideology were also identified. Smart-glasses are envisioned to change individual human identity and behavior as well as social interaction. Taking these issues into account appears to be crucial for fruitful development, assessment, decision making, implementation, use, and formation of knowledge and norms with respect to smart-glasses.

\section{Acknowledgement}

This study has been supported by Naturalness in Human Cognitive Enhancement Czech-Norwegian Research Programme CZ09, project number 7F14236.

\section{Contributions}

$\mathrm{BH}$ designed the study and performed the literature search. $\mathrm{BH}, \mathrm{DH}$, and $\mathrm{LL}$ performed the screening and the analysis of the literature. $\mathrm{BH}$ wrote the first draft of the paper. All authors have contributed to the revision of the paper and have approved the final version.

\section{References}

Ackerman, E. (2012, December 31 2012). Why Smart Glasses Might Not Make You Smarter. IEEE Spectrum.

Ajmi, A., \& Robak, M. J. (2015). Google Glass FOR THE Educator: A Postmortem Separating the Reality From the Hype and Some Thoughts for Google. Computers in libraries, 35(3), 12-15.

Allhoff, F., Lin, P., Moor, J., \& Weckert, J. (2009). Ethics of human enhancement: 25 questions \& answers. Studies in Ethics, Law, and Technology, 4(1).

Arnold, R., Hillebrand, A., \& Waldburger, M. (2015). Personal Data and Privacy. Study for Ofcom, WIK-Consult, May.

Bailey, D. E. (2014). Hyperreality: The merging of the physical and digital worlds.

Behar-Cohen, F., Martinsons, C., Viénot, F., Zissis, G., Barlier-Salsi, A., Cesarini, J., et al. (2011). Lightemitting diodes (LED) for domestic lighting: Any risks for the eye? Progress in retinal and eye research, 30(4), 239-257.

Bendel, O. (2014). Die Datenbrille aus Sicht der Informationsethik. Informatik-Spektrum, 1-9.

Benessia, A., \& Pereira, Â. G. (2015). 5 the dream of the Internet of things. Science, Philosophy and Sustainability: The End of the Cartesian Dream, 78.

Bergman, K. (2013). Cyborgs in the Courtroom: The Use of Google Glass Recordings in Litigation. Rich. JL \& Tech., 20, 1. 
Betancourt, A., Morerio, P., Regazzoni, C. S., \& Rauterberg, M. (2015). The Evolution of First Person Vision Methods: A Survey.

Bieber, M., Cai, X., Collins, R., Hiltz, S., Liu, Y., \& Sanchez Suasnabar, E. (2015). How Hands Free Always On (HFAO) Technology Will Affect Classrooms.

Boenink, M., Swierstra, T., \& Stemerding, D. (2010). Anticipating the interaction between technology and morality: A scenario study of experimenting with humans in bionanotechnology. Studies in Ethics, Law, and Technology, 4(2).

Boissier, O., \& Castelfranchi, C. Mirror Worlds as Agent Societies Situated in Mixed Reality Environments. In Coordination, Organizations, Institutions, and Norms in Agent Systems X: COIN 2014 International Workshops, COIN@ AAMAS, Paris, France, May 6, 2014, COIN@ PRICAI, Gold Coast, QLD, Australia, December 4, 2014, Revised Selected Papers, 2015 (Vol. 9372, pp. 197): Springer

Borean, C., Giannantonio, R., Mamei, M., Mana, D., Sassi, A., \& Zambonelli, F. (2015). Urban Crowd Steering: An Overview. In Internet and Distributed Computing Systems (pp. 143-154): Springer.

Bozyer, Z. (2015). Augmented Reality in Sports: Today and Tomorrow. International Journal of Science Culture and Sport (IntJSCS), 3(4), 314-325.

Cajochen, C., Frey, S., Anders, D., Spati, J., Bues, M., Pross, A., et al. (2011). Evening exposure to a light-emitting diodes (LED)-backlit computer screen affects circadian physiology and cognitive performance. J Appl Physiol (1985), 110(5), 1432-1438, doi:10.1152/japplphysiol.00165.2011.

Chalfen, R. (2014). 'Your panopticon or mine?'Incorporating wearable technology's Glass and GoPro into visual social science. Visual Studies, 29(3), 299-310.

Chang, C.-H., Pan, W.-W., Tseng, L.-Y., \& Stoffregen, T. A. (2012). Postural activity and motion sickness during video game play in children and adults. Experimental brain research, 217(2), 299-309.

Dainow, B. (2014). Ethics in Emerging Technology. ITNow, 56(3), 16-18.

Dauber, B., Meyer, P., \& Kindsmüller, M. C. The potential of smart glasses for smart homes. In Mensch und Computer 2014-Tagungsband: 14. Fachübergreifende Konferenz für Interaktive und Kooperative Medien-Interaktiv unterwegs-Freiräume gestalten, 2014 (pp. 379): Walter de Gruyter GmbH \& Co KG

Doherty, A., Williamson, W., Hillsdon, M., Hodges, S., Foster, C., \& Kelly, P. Influencing health-related behaviour with wearable cameras: strategies \& ethical considerations. In Proceedings of the 4th International SenseCam \& Pervasive Imaging Conference, 2013 (pp. 60-67): ACM

Due, B. Challenges with Google Glass in social interaction. In 4TH PARTICIPATORY INNOVATION CONFERENCE 2015, the Hague, 2015 (pp. 440-448)

Due, B. L. (2014). The future of smart glasses:: An essay about challenges and possibilities with smart glasses. Working papers on interaction and communication, 1(2), 1-21.

Edington, D. W., Schultz, A. B., Pitts, J. S., \& Camilleri, A. (2015). The Future of Health Promotion in the 21st Century A Focus on the Working Population. American Journal of Lifestyle Medicine, 1559827615605789.

Egenhofer, M. Spatial information appliances: A next generation of geographic information systems. In 1st Brazilian workshop on geoinformatics, Campinas, Brazil, 1999

Egenhofer, M. J., \& Kuhn, W. (1998). Beyond desktop GIS. GIS PlaNET, Lisbon, Portugal.

Falahee, M., Latham, K., \& Geelhoed, E. (2000). Safety and Comfort of Eyeglass Displays. In P. Thomas, \& H.-W. Gellersen (Eds.), Handheld and Ubiquitous Computing (Vol. 1927, pp. 236-247, Lecture Notes in Computer Science): Springer Berlin Heidelberg.

Farinella, G. M., Allegra, D., \& Stanco, F. A Benchmark Dataset to Study the Representation of Food Images. In Computer Vision-ECCV 2014 Workshops, 2014 (pp. 584-599): Springer

Forte, A. G., Garay, J. A., Jim, T., \& Vahlis, Y. (2014). EyeDecrypt-Private Interactions in Plain Sight. In Security and Cryptography for Networks (pp. 255-276): Springer. 
Freina, L., \& Ott, M. (2015). A Literature Review on Immersive Virtual Reality in Education: State Of The Art and Perspectives. Proceedings of eLearning and Software for Education (eLSE)(Bucharest, Romania, April 23--24, 2015).

Friedland, S. (2013). Cell Phone Searches in a Digital World: Blurred Lines, New Realities and Fourth Amendment Pluralism.

Friedland, S. I. (2015). I Spy: The New Self-Cybersurveillance. Wash. \& Lee L. Rev., 72, 1459.

Gallitano, L. (2015). Our Bodies, Our Quantified Selves: A Sociological Analysis of Wearable Technology.

Garcia, T., \& Sandler, R. (2008). Enhancing justice? Nanoethics, 2(3), 277-287.

Geels, F. W. (2005). Technological transitions and system innovations: a co-evolutionary and sociotechnical analysis: Edward Elgar Publishing.

Gehmann, U., Zampella, M., \& Wolfel, M. Liberated Formatization. In Cyberworlds (CW), 2014 International Conference on, 2014 (pp. 332-339): IEEE

Gehmann, U., Zampella, M., \& Wölfel, M. (2015). Formatization Unleashed. Analyzing Art, Culture, and Design in the Digital Age, 219.

Gemming, L., Doherty, A., Kelly, P., Utter, J., \& Mhurchu, C. N. (2013). Feasibility of a SenseCamassisted 24-h recall to reduce under-reporting of energy intake. European journal of clinical nutrition, 67(10), 1095-1099.

Gill, S. P. (2015). Tacit engagement. In Tacit Engagement (pp. 1-34): Springer.

Gillespie, A., \& O'Neill, B. (2014). THE FUTURE OF ASSISTIVE TECHNOLOGY FOR COGNITION. Assistive Technology for Cognition: A Handbook for Clinicians and Developers, 160.

Harasymowicz, P. M. Outernet Technologies in Tourism: A Conceptual Framework and Applications for the Travel Industry. In ISCONTOUR 2015-Tourism Research Perspectives: Proceedings of the International Student Conference in Tourism Research, 2015 (pp. 97): BoD-Books on Demand

Harg, B. (2014). Augmented postphenomenology: a (post) phenomenological and ethical exploration of Google Glass.

Haris, M., Haddadi, H., \& Hui, P. (2014). Privacy Leakage in Mobile Computing: Tools, Methods, and Characteristics. arXiv preprint arXiv:1410.4978.

He, H., Li, Y., Guan, Y., \& Tan, J. (2015). Wearable Ego-Motion Tracking for Blind Navigation in Indoor Environments. Automation Science and Engineering, IEEE Transactions on, 12(4), 1181-1190.

Hedegaard Hansen, J., Ngugen, T., Nicholson, K., Sandlykke, L., Skytte Hansen, C., \& Valeur, I. (2014). Mediated Life after Virtualization.

Henderson, J. M., Shinkareva, S. V., Wang, J., Luke, S. G., \& Olejarczyk, J. (2013). Predicting cognitive state from eye movements.

Hetterich, C., Pobiruchin, M., Wiesner, M., \& Pfeifer, D. (2014). How Google Glass Could Support Patients with Diabetes Mellitus in Daily Life. EHealth-For Continuity of Care: Proceedings of MIE2014, 205, 298.

Higuchi, T., Iwahashi, H., Yamaguchi, H., \& Higashino, T. TweetGlue: Leveraging a crowd tracking infrastructure for mobile social augmented reality. In Wireless Communications and Mobile Computing Conference (IWCMC), 2015 International, 2015 (pp. 1030-1035): IEEE

Hildebrandt, M. (2014). Criminal Law and Technology in a Data-Driven Society.

Hofmann, B. (2002). Is there a technological imperative in health care? [Vitenskapelig artikkel]. Int J Technol Assess Health Care, 18(3), 675-689.

Hofmann, B. (Submitted 2016). Toward a method for addressing ethical issues in the assessment of human cognitive enhancement as a type of emerging technology. Sci Eng Ethics.

Hofmann, B., Droste, S., Oortwijn, W., Cleemput, I., \& Sacchini, D. (2014). Harmonization of ethics in health technology assessment: a revision of the Socratic approach. Int J Technol Assess Health Care, 30(1), 3-9, doi:10.1017/\$0266462313000688.

Hsieh, H. F., \& Shannon, S. E. (2005). Three approaches to qualitative content analysis. Qual Health Res, 15(9), 1277-1288, doi:10.1177/1049732305276687. 
Huang, J. (2013). RealTime HDR (High Dynamic Range) Image Processing For Digital Glass Seeing Aid. University of Toronto,

Huff, S. L., \& Munro, M. C. (1985). Information technology assessment and adoption: a field study. MIS quarterly, 327-340.

Ihde, D., Langsdorf, L., Besmer, K. M., Hoel, A. S., Carusi, A., Nizzi, M.-C., et al. (2015). Postphenomenological Investigations: Essays on Human-Technology Relations: Lexington Books.

Ikonen, J., \& Knutas, A. Exploring Wearable Cameras for Educational Purposes.

Irving, L., \& Hoffman, J. (2014). Nyungar Place Stories Pilot: using augmented reality for Indigenous cultural sustainability. Rethoric and Reality.

Iwamura, M., Kunze, K., Kato, Y., Utsumi, Y., \& Kise, K. Haven't we met before?: a realistic memory assistance system to remind you of the person in front of you. In Proceedings of the 5th Augmented Human International Conference, 2014 (pp. 32): ACM

Jacquemard, T., Novitzky, P., O'Brolcháin, F., Smeaton, A. F., \& Gordijn, B. (2014). Challenges and opportunities of lifelog technologies: a literature review and critical analysis. Sci Eng Ethics, 20(2), 379-409.

Jones, T. (2014). LIGHTWEIGHT AUGMENTED REALITY: AN INVESTIGATION INTO AR-CAPABLE HEADMOUNTED DISPLAYS. Flinders University-Adelaide Australia,

Kaeri, Y., Sugawara, K., Manabe, Y., \& Moulin, C. Prototyping a meeting support system using ubiquitous agents. In Computer Supported Cooperative Work in Design (CSCWD), 2015 IEEE 19th International Conference on, 2015 (pp. 18-23): IEEE

Karabiyik, U. (2015). Building an intelligent assistant for digital forensics. THE FLORIDA STATE UNIVERSITY,

Keane, J. (2013). Democracy and media decadence: Cambridge University Press.

Kelly, P., Marshall, S. J., Badland, H., Kerr, J., Oliver, M., Doherty, A. R., et al. (2013). An ethical framework for automated, wearable cameras in health behavior research. American journal of preventive medicine, 44(3), 314-319.

Kiran, A. H., Oudshoorn, N., \& Verbeek, P.-P. (2015). Beyond checklists: toward an ethicalconstructive technology assessment. Journal of Responsible Innovation, 2(1), 5-19.

Klein, G. O., Singh, K., \& von Heideken, J. (2015). Smart Glasses--A New Tool in Medicine. Stud Health Technol Inform, 216, 901.

Koelle, M., Kranz, M., \& Möller, A. Don't look at me that way!-Understanding User Attitudes Towards Data Glasses Usage.

Koper, R. (2014). Conditions for effective smart learning environments. Smart Learning Environments, 1(1), 1-17.

Koren, I., \& Klamma, R. Smart Ambient Learning with Physical Artifacts Using Wearable Technologies. In 11th International Conference on Intelligent Environments, 2015 (pp. 325)

Kotsios, A. (2015). Privacy in an augmented reality. International Journal of Law and Information Technology, 23(2), 157-185.

Kruijsen, T. (2008). Automatic for the people: the effects of smart surroundings on the autonomy of people.

Kumar, G., \& Sharma, P. (2014). Google Glasses Impediments. medicine, 1(2).

Kunze, K., Sanchez, S., Dingler, T., Augereau, O., Kise, K., Inami, M., et al. The augmented narrative: toward estimating reader engagement. In Proceedings of the 6th Augmented Human International Conference, 2015 (pp. 163-164): ACM

Labus, A., Milutinovic, M., Stepanic, Đ., Stevanovic, M., \& Milinovic, S. (2015). WEARABLE COMPUTING IN E-EDUCATION. RUO. Revija za Univerzalno Odlicnost, 4(1), A39.

Lee, Y., \& Balan, R. K. The case for human-centric personal analytics. In Proceedings of the 2014 workshop on physical analytics, 2014 (pp. 25-29): ACM

Lerch, N. (2014). Sousveillance and its impact on privacy.

Liberati, N., \& Nagataki, S. (2015). The AR glasses' "non-neutrality": their knock-on effects on the subject and on the giveness of the object. Ethics and Information Technology, 17(2), 125-137. 
Ling, R., Mardanbeigi, D., \& Hansen, D. W. (2014). Synergies between head-mounted displays and head-mounted eye tracking: The trajectory of development and its social consequences. LIVING, 131.

Lucivero, F., \& Vedder, A. (2013). Beyond therapy v. enhancement?: multidisciplinary analyses of heated debate.

Maas, S., Ingler, M., \& Overhoff, H. M. (2015). Using smart glasses for ultrasound diagnostics. Current Directions in Biomedical Engineering, 1(1), 196-197.

Mann, S. (2012). Through the glass, lightly [viewpoint]. Technology and Society Magazine, IEEE, 31(3), 10-14.

Mann, S. Veilance and reciprocal transparency: Surveillance versus sousveillance, AR glass, lifeglogging, and wearable computing. In Technology and Society (ISTAS), 2013 IEEE International Symposium on, 2013 (pp. 1-12): IEEE

Mann, S. (2013). Veillance: Beyond Surveillance, Dataveillance. Uberveillance and the Social Implications of Microchip Implants: Emerging Technologies: Emerging Technologies, 32.

Mann, S. (2014). Wearable Computing. In M. Soegaard, \& R. F. Dam (Eds.), The Encyclopedia of Human-Computer Interaction. Aarhus, Denmark: The Interaction Design Foundation.

Mann, S., \& Ferenbok, J. (2013). New Media and the power politics of sousveillance in a surveillancedominated world. Surveillance \& Society, 11(1/2), 18-34.

Mann, S., \& Hrelja, M. Praxistemology: Early childhood education, engineering education in a university, and universal concepts for people of all ages and abilities. In Technology and Society (ISTAS), 2013 IEEE International Symposium on, 2013 (pp. 86-97): IEEE

Mann, S., Ratto, M., \& Boler, M. (2014). Maktivism: Authentic making for technology in the service of humanity. DIY Citizenship: Critical Making and Social Media, 29-52.

Marken, A. (2015). You aren't what you wear.

Markov, M. S. (2015). Benefit and Hazard of Electromagnetic Fields. Electromagnetic Fields in Biology and Medicine, 15.

McKenna, H. P., Arnone, M. P., \& Chauncey, S. A. 2013 IEEE International Symposium on Technology and Society (ISTAS).

Mentler, T., Wolters, C., \& Herczeg, M. (2015). Use cases and usability challenges for head-mounted displays in healthcare. Current Directions in Biomedical Engineering, 1(1), 534-537.

Michael, K. (2013). Social Implications of Wearable Computing and Augmediated Reality in Every Day Life (IEEE Symposium on Technology and Society, ISTAS13).

Milgram, P., Takemura, H., UTSUMI, A., \& KISHINO, F. (2012). Augmented reality: A class of displays on the reality-virtuality continuum, 1994. SPIE Proceedings Tele-manipulator and Telepresence Technologies, 2351.

Mitrasinovic, S., Camacho, E., Trivedi, N., Logan, J., Campbell, C., Zilinyi, R., et al. (2015). Clinical and surgical applications of smart glasses. Technology and Health Care(Preprint), 1-21.

Mitrasinovic, S., Camacho, E., Trivedi, N., Logan, J., Campbell, C., Zilinyi, R., et al. (2015). Clinical and surgical applications of smart glasses. Technol Health Care, 23(4), 381-401, doi:10.3233/thc150910.

Moghaddam, R. F., Moghaddam, F. F., Dandres, T., Lemieux, Y., Samson, R., \& Cheriet, M. (2014). Challenges and complexities in application of LCA approaches in the case of ICT for a sustainable future. arXiv preprint arXiv:1403.2798.

Morozov, E. (2013). To save everything, click here: Technology, solutionism, and the urge to fix problems that don't exist: Penguin UK.

Morozov, E. (2014). To save everything, click here: The folly of technological solutionism: PublicAffairs.

Moshtaghi, O., Kelley, K. S., Armstrong, W. B., Ghavami, Y., Gu, J., \& Djalilian, H. R. (2015). Using google glass to solve communication and surgical education challenges in the operating room. The Laryngoscope.

Muschiol, J. (2015). Universal Communication model and evaluation with the Elderly Society. Universidad Católica San Antonio de Murcia, Murcia.

Naydler, J. (2013). The advent of the wearable computer. Self \& Society, 40(3), 17-24. 
Neira Millan, O. J. (2013). Mobile Augmented Reality Application for Monitoring Industrial Systems. Tampere University of Technology, Tampere.

Nikolov, P. (2013). The effect of concurrent cognitive-visuomotor multitasking and task difficulty on dynamic functional connectivity in the brain.

Noble, S. U., \& Roberts, S. T. (2016). Through Google-Colored Glass (es): Design, Emotion, Class, and Wearables as Commodity and Control.

Nyang, D., Mohaisen, A., \& Kang, J. (2014). Keylogging-resistant visual authentication protocols. Mobile Computing, IEEE Transactions on, 13(11), 2566-2579.

Organization, W. H. (2011). Electromagnetic fields and public health: mobile phones (Fact sheet no. 193). World Health Organization [cited 29 May 2014]. Available at: http://www. who. int/mediacentre/factsheets/fs193/en/CITO042.

Ostendorp, M.-C., Lenk, J. C., \& Lüdtke, A. (2015). Smart Glasses to Support Maritime Pilots in Harbor Maneuvers. Procedia Manufacturing, 3, 2840-2847.

Oudshoorn, N., \& Pinch, T. (2003). How users matter: the co-construction of users and technology (inside technology): the MIT Press.

Page, T. (2015). Barriers to the Adoption of Wearable Technology. i-Manager's Journal on Information Technology, 4(3), 1.

Palm, E., \& Hansson, S. O. (2006). The case for ethical technology assessment (eTA). Technological forecasting and social change, 73(5), 543-558.

Pan, C. W., Ramamurthy, D., \& Saw, S. M. (2012). Worldwide prevalence and risk factors for myopia. Ophthalmic and Physiological Optics, 32(1), 3-16.

Paterson, M., \& Glass, M. R. (2015). The world through Glass: developing novel methods with wearable computing for urban videographic research. Journal of Geography in Higher Education(ahead-of-print), 1-13.

Pedersen, I. (2013). Ready to Wear: A Rhetoric of Wearable Computers and Reality-Shifting Media: Parlor Press.

Pejovic, V., Mehrotra, A., \& Musolesi, M. (2015). Anticipatory Mobile Digital Health: Towards Personalised Proactive Therapies and Prevention Strategies. arXiv preprint arXiv:1508.03722.

Pereira, Â. G., Benessia, A., \& Curvelo, P. (2013). Agency in the Internet of Things: Publications Office.

Ranck, J. (2012). The wearable computing market: a global analysis. Gigaom Pro.

Rankin, T. M., Slepian, M. J., \& Armstrong, D. G. (2015). Augmented Reality in Surgery. In Technological Advances in Surgery, Trauma and Critical Care (pp. 59-71): Springer.

Renzi, A. B., \& de Freitas, S. F. (2015). Delphi Method to Explore Future Scenario Possibilities on Technology and $\mathrm{HCl}$. In Design, User Experience, and Usability: Design Discourse (pp. 644653): Springer.

Ricci, A., Piunti, M., Tummolini, L., \& Castelfranchi, C. (2015). The Mirror World: Preparing for MixedReality Living. IEEE Pervasive Computing(2), 60-63.

Roesner, F., Kohno, T., Denning, T., Calo, R., \& Newell, B. C. Augmented reality: Hard problems of law and policy. In Proceedings of the 2014 ACM International Joint Conference on Pervasive and Ubiquitous Computing: Adjunct Publication, 2014 (pp. 1283-1288): ACM

Romano, Z., \& Cangiano, S. (2015). Open Sourcing Wearables. In Empowering Users through Design (pp. 153-175): Springer.

Rosenberger, R., \& Verbeek, P.-P. (2015). A Field Guide to Postphenomenology. Postphenomenological Investigations: Essays on Human-Technology Relations, 9.

Sapargaliyev, D. (2015). Learning with Wearable Technologies: A Case of Google Glass. In The Mobile Learning Voyage-From Small Ripples to Massive Open Waters (pp. 343-350): Springer.

Satyanarayanan, M., Simoens, P., Xiao, Y., Pillai, P., Chen, Z., Ha, K., et al. (2015). Edge Analytics in the Internet of Things. IEEE Pervasive Computing(2), 24-31.

Sehgal, V. K., Patrick, A., Soni, A., \& Rajput, L. (2015). Smart Human Security Framework Using Internet of Things, Cloud and Fog Computing. In Intelligent Distributed Computing (pp. 251263): Springer. 
Shang, Y. M., Wang, G. S., Sliney, D., Yang, C. H., \& Lee, L. L. (2014). White light-emitting diodes (LEDs) at domestic lighting levels and retinal injury in a rat model. Environ Health Perspect, 122(3), 269-276, doi:10.1289/ehp.1307294.

Shen, C., Pei, S., Yang, Z., \& Guan, X. (2015). Input extraction via motion-sensor behavior analysis on smartphones. Computers \& Security, 53, 143-155.

Singh, K., Klein, G. O., \& Johan von Heideken, M. Google Glass Has Potential for Rheumatology, Orthopedic Surgery.

Sliney, D. H. (1984). Quantifying retinal irradiance levels in light damage experiments. Curr Eye Res, 3(1), 175-179.

Sollie, P., \& Düwell, M. (2009). Evaluating New Technologies: Methodological Problems for the Ethical Assessment of Technology Developments (Vol. 3): Springer Science \& Business Media.

Speed, T., Nykamp, D., Anderson, J., Nampalli, J., \& Heiser, M. (2013). Mobile Security: How to secure, privatize and recover your devices: Packt Publishing Ltd.

Strech, D., \& Sofaer, N. (2012). How to write a systematic review of reasons. J Med Ethics, 38(2), 121126.

Sultan, N. (2015). Reflective thoughts on the potential and challenges of wearable technology for healthcare provision and medical education. International Journal of Information Management, 35(5), 521-526.

Swierstra, T. (2015). Identifying the normative challenges posed by technology's 'soft' impacts. Nord J Appl Ethics, 9(1), 5-20.

Swierstra, T., Stemerding, D., \& Boenink, M. (2009). Exploring techno-moral change: the case of the obesitypill. In Evaluating new technologies (pp. 119-138): Springer.

Swierstra, T., \& te Molder, H. (2012). Risk and soft impacts. In Handbook of risk theory (pp. 10491066): Springer.

Takei, K., Honda, W., Harada, S., Arie, T., \& Akita, S. (2015). Toward Flexible and Wearable Human Interactive Health - Monitoring Devices. Advanced healthcare materials, 4(4), 487-500.

Teehan, P. (2014). Integrative approaches to environmental life cycle assessment of consumer electronics and connected media.

Thiel, C., \& Thiel, C. (2014). Enforcing Data Privacy in the Age of Google Glass. In ISSE 2014 Securing Electronic Business Processes (pp. 220-229): Springer.

Triberti, S., Repetto, C., \& Riva, G. (2014). Psychological Factors Influencing the Effectiveness of Virtual Reality-Based Analgesia: A Systematic Review. Cyberpsychology, Behavior, and Social Networking, 17(6), 335-345.

Tse, M. M., Ng, J. K., Chung, J. W., \& Wong, T. K. (2002). The effect of visual stimulation via the eyeglass display and the perception of pain. CyberPsychology \& Behavior, 5(1), 65-75.

Tunçalp, D., \& Fagan, M. H. (2014). Anticipating Human Enhancement: Identifying Ethical Issues of Bodyware. Global Issues and Ethical Considerations in Human Enhancement Technologies, 16.

Ugulino, W., \& Fuks, H. Landmark identification with wearables for supporting spatial awareness by blind persons. In Proceedings of the 2015 ACM International Joint Conference on Pervasive and Ubiquitous Computing, 2015 (pp. 63-74): ACM

Valente, L., Feijó, B., \& do Prado Leite, J. C. S. (2015). Mapping quality requirements for pervasive mobile games. Requirements Engineering, 1-29.

van der Burg, S. (2009). Taking the "soft impacts" of technology into account: Broadening the discourse in research practice. Social Epistemology, 23(3-4), 301-316.

Verbeek, P.-P. Beyond interaction.

Verbeek, P.-P. (2011). Moralizing technology: Understanding and designing the morality of things: University of Chicago Press.

Verbeek, P.-P. (2015). COVER STORY Beyond interaction: a short introduction to mediation theory. interactions, 22(3), 26-31.

Wassom, B. (2014). Augmented Reality Law, Privacy, and Ethics: Law, Society, and Emerging AR Technologies: Syngress. 
Weber, H., \& Zink, K. J. (2014). Boon and Bane of ICT Acceleration for Vulnerable Populations. In The Impact of ICT on Quality of Working Life (pp. 177-190): Springer.

Welinder, Y. (2013). Facing Real-Time Identification in Mobile Apps \& Wearable Computers. Santa Clara High Tech. LJ, 30, 89.

Wolf, K., Schmidt, A., Bexheti, A., \& Langheinrich, M. (2014). Lifelogging: You're Wearing a Camera? Pervasive Computing, IEEE, 13(3), 8-12.

Yoon, H., Shin, D.-H., \& Kim, H. (2015). Health Information Tailoring and Data Privacy in a Smart Watch as a Preventive Health Tool. In Human-Computer Interaction: Users and Contexts (pp. 537-548): Springer.

Zhan, K. (2014). First-Person Activity Recognition.

Zhang, L., Li, X.-Y., Huang, W., Liu, K., Zong, S., Jian, X., et al. It starts with igaze: Visual attention driven networking with smart glasses. In Proceedings of the 20th annual international conference on Mobile computing and networking, 2014a (pp. 91-102): ACM

Zhang, L., Liu, K., Li, X.-Y., Feng, P., Liu, C., \& Liu, Y. (2014b). Enable Portrait Privacy Protection in Photo Capturing and Sharing. arXiv preprint arXiv:1410.6582. 